\title{
Much to do with nothing: microsimulation study on time management in primary care
}

\author{
Tanner J Caverly, ${ }^{1,2,3,4}$ Rodney A Hayward, 1,2,4 James F Burke 1,2,5
}

Check for updates

${ }^{1}$ VA Center for Clinical

Management Research, Ann

Arbor, Michigan, USA

${ }^{2}$ Institute for Health Policy

Innovation, University of

Michigan School of Medicine,

2800 Plymouth Rd, Building

16, Ann Arbor, MI 48109, USA

${ }^{3}$ Department of Learning Health Sciences, University of Michigan

School of Medicine, MI, USA

${ }^{4}$ Department of Internal

Medicine, University of

Michigan School of Medicine,

MI, USA

${ }^{5}$ Department of Neurology,

University of Michigan School

of Medicine and Ann Arbor VA

Medical Center, MI, USA

Correspondence to:

tcaverly@med.umich.edu

(or @tanner_caverly on Twitter:

ORICD 0000-0002-6560-0547)

Additional material is published online only. To view please visit

the journal online.

Cite this as: $B M J$ 2018;363:k4983

http://dx.doi.org/10.1136/bmj.k4983

Accepted: 22 November 2018

\section{ABSTRACT}

OBJECTIVE

To investigate the credibility of claims that general practitioners lack time for shared decision making and preventive care.

DESIGN

Monte Carlo microsimulation study.

SETTING

Primary care, United States.

\section{PARTICIPANTS}

Sample of general practitioners $(n=1000)$

representative of annual work hours and patient panel size ( $n=2000$ patients) in the US, derived from the National Health and Nutrition Examination Survey.

\section{MAIN OUTCOME MEASURES}

The primary outcome was the time needed to deliver shared decision making for highly recommended preventive interventions in relation to time available for preventive care-the prevention-time-space-deficit (ie, time-space needed by doctor exceeding the timespace available).

\section{RESULTS}

On average, general practitioners have 29 minutes each workday to discuss preventive care services (just over two minutes for each clinic visit) with patients, but they need about 6.1 hours to complete shared decision making for preventive care. $100 \%$ of the study sample experienced a prevention-timespace-deficit (mean deficit $5.6 \mathrm{~h} /$ day) even given conservative (ie, absurdly wishful) time estimates for shared decision making. However, this time deficit could be easily overcome by reducing personal time and shifting gains to work tasks. For example, general practitioners could reduce the frequency of bathroom breaks to every other day and skip time with older children who don't like them much anyway.

\section{WHAT IS ALREADY KNOWN ON THIS TOPIC}

General practitioners often grouse about not having enough time for shared decision making and preventive care services

When doctors have been observed in their natural state, however, their idleness rivals that of the koala, which sleeps 22 hours a day

This paradox has long befuddled researchers and clinical managers: are doctors doing their best as they claim, or are they playing coy with vast amounts of idle time?

\section{WHAT THIS STUDY ADDS}

The time needed for shared decision making for all highly recommended preventive services hugely exceeds the time available-and this time deficit is due to doctors spending too few hours working

If clinical managers learn how to exploit the expansive reservoir of a doctor's personal time, such as time "relaxing and thinking," there will be ample time for shared decision making and for many other new clinical tasks

\section{CONCLUSION}

This study confirms a widely held suspicion that general practitioners waste valuable time on "personal care" activities. Primary care overlords, once informed about the extent of this vast reservoir of personal time, can start testing methods to "persuade" general practitioners to reallocate more personal time toward bulging clinical demands.

\section{Introduction}

A widely held presumption is that general practitioners have too much to do and too little time. ${ }^{1-7}$ Strangely, no research has asked the obvious follow-up questions: Have they no evenings? Have they no weekends? As with most humans, doctors seek out the course of action that uses up as little time and energy as possible ${ }^{8}$-in other words they are lazy (see the trigger warning at the end of the article before proceeding). Doctors therefore have a large, untapped reservoir of time. The central challenge of disruptive healthcare leadership, then, is to find ways of tapping into that reservoir and draining it dry. Draining stagnant time allows managers to refill a doctor's workday to the brim with fresh streams of important new clinical tasks! For example, one fewer toilet breaks enable the completion of as many as five additional clinical alerts (up to 10 more for older men).

Despite having an untapped reservoir of time, doctors never stop mewling about the time needed for shared decision making, ${ }^{9-12}$ especially for preventive care. Shared decision making is defined by the US Preventive Services Task Force (a panel of experts who make evidence based recommendations on preventive care services) as "a particular process of decision making by the patient and clinician in which the patient: 1) understands the risk or seriousness of the disease or condition to be prevented; 2) understands the preventive service, including the risks, benefits, alternatives, and uncertainties; 3) has weighed his or her values regarding the potential benefits and harms associated with the service; and 4) has engaged in decision making at a level at which he or she desires and feels comfortable." ${ }^{2}$ Asking doctors to engage in shared decision making for preventive services is like asking a toddler to share candy with a sibling; no matter how big the bag there's going to be moaning and wailing. A recent study reported that doctors spent an average of only 59 seconds on shared decision making for lung cancer screening, despite it being known by experts that five minutes is the absolute minimum. ${ }^{13}$ Even without shared decision making, doctors still grouse about a lack of time to deliver basic preventive care. ${ }^{14-16}$ Yet, few studies have examined the basis for these whimpering protestations. One study estimated that to deliver all recommended preventive services 
to a typical patient panel, doctors need an average of 7.4 hours each workday. ${ }^{17}$ This average seems large, but one working day is a tiny slice of a doctor's time on the planet. Cutting back on weekend naps could solve the problem entirely! Careful review of what is known about the daily lives of doctors is the only way to tell whether these "time-deprived" grievances lack credence. So, following in the long tradition of data driven management, we commissioned a study to quantify precisely what we already know-that doctors have vast amounts of time for thumb twiddling.

At a moment when doctors are shirking responsibilities while grumbling that their overlords are unreasonable in demanding more, it has become urgent to examine the actual life of the doctor. We carried out a microsimulation study to examine their time management and how this affects shared decision making for highly recommended preventive interventions.

\section{Methods}

We created a Monte Carlo microsimulation model to examine the time needed to deliver shared decision making forhighlyrecommended preventiveinterventions (as recommended by the US Preventive Services Task Force to a representative panel of patients) and the time available to doctors for such care, using a representative sample of US general practitioners with a wide range of annual work hours ${ }^{18}$ (from honeybee-type (frenetic) to koala-type (more leisurely) workers). Provided a few stalwarts can accommodate shared decision making for highly recommended preventive care, coercing the rest to do so should be straightforward. Public shaming is a well established and effective method for motivating the lazy, ${ }^{19}$ but only if accompanied by severe punishment of stragglers. ${ }^{20}$ Compelled by common practice in this research area (and to inform doctor replacement strategies), we looked at a theoretical downside of piling on more tasks-burnout, a negative emotional response to prolonged occupational stress, ${ }^{21}$ and a commonly used surrogate measure of dubious clinical importance. Lastly, to identify potential targets for shoring up deficits in delivering shared decision making for preventive care, we explored how general practitioners allocate work and non-work time across a typical day. ${ }^{22}$

\section{Microsimulation model}

To create a realistic, nationally representative patient panel we randomly selected participants from the patient population of the National Health and Nutrition Examination Survey. ${ }^{23}$ In accordance with common managerial practice, we pretended that fulltime doctors manage fewer patients than they actually do (ie, 2000 annually). The number of visits were assigned to each patient by random draws from age and sex based visit frequencies. ${ }^{24}$ For each patient, we estimated the total time needed for prevention and shared decision making by determining what preventive care services were needed at a given visit and summing preventive care and shared decision making times at each visit. We simulated a mature panel by building 10 years of visits under realistic panel retention and replacement rates. ${ }^{25}$ Time inputs were taken from published literature and YouTube. ${ }^{17} 2627$ We consistently used time estimates on the extreme lower end of what is realistically required (ie, time estimates ignore clinical reality). However, minimizing doctors' tasks is a standard methodology. The supplemental methods and table S.1 provide full detail on the microsimulation and model inputs.

\section{Statistical analyses}

We assessed the face validity of key model outputs to ensure the model was performing well (ie, agreeing with pre-existing biases) and providing the basis for reasonable total time estimates, estimating model precision accounting for uncertainty in baseline inputs. We analyzed variation between general practitioners by assessing the prevention-time-spacedeficit (amount of distortion surrounding a doctor as a result of the time-space needed exceeding the time-space available) across doctors in the study population, calculating the proportion of those who were able to stay above water (ie, no prevention-timespace-deficit). In sensitivity analyses, we explored the impact of various corner cutting strategies. We also analyzed the impact of the additional hours of worktime on rates of doctor burnout. In an ominous note for doctors, it took our snappy computer (which did not take any bathroom breaks) a weekend just to simulate these tasks.

Some conclusions, such as the statement that any doctors with a time deficit work too few hours, did not require analysis. Instead, to support this claim we simply defined "true" doctors as those who work enough hours to complete shared decision making for all highly recommended preventive care services (also see the "no true Scotsman" fallacy ${ }^{28}$ ). Thus, by definition, a doctor who was not able to get the job done was either not a true doctor or was not working enough hours. We also used this nifty self reinforcing definition to justify reductions in general practitioners' personal time. Clinical managers interested in applying this underutilized method to make strong, non-falsifiable claims should review the Scotsman fallacy.

\section{Patient and public involvement}

No patients were involved in setting the research question or the outcome measures, nor were they involved in developing plans for design or implementation of the study. No patients were asked to advise on interpretation or writing up of results. There are no plans to disseminate the results of the research to study participants or the relevant patient community.

\section{Results}

Face validity of model outputs

Our estimates for frequency of visits and preventive care services had excellent face validity (ie, they looked 
good to us without the data even being manipulated!). Of an average doctors' 2000 patient panel, 1640 $(82.0 \%)$ patients were seen at least once in a given 12 month period. The median number of visits per patient in the past year was 2 (interquartile range 1-3) and the median number of preventive care services received was 7 (5-11).

Time available and time needed for preventive care Each workday, doctors have about 29 minutes to discuss preventive care services-or just over two minutes on average for each clinic visit. However, the time needed to complete shared decision making for all preventive services is about 366 minutes (6.1 hours) per workday, or 26 minutes for each visit. To break even the average doctor thus needs to find slightly more than 300 extra minutes each workday. Supplemental table S.1 presents the amount of time each year used for shared decision making, by preventive service.

\section{Variation in prevention-time-space-deficit across doctors}

Figure 1 depicts the degree to which study doctors stayed within the laws of physics (no time-space deficit). We were surprised, but still skeptical, when we found that $0.0 \%$ of them could avoid the dreaded prevention-time-space-deficit (mean deficit $5.6 \mathrm{~h} /$ day) even given our optimistically low estimate of time needed for full shared decision making.

\section{Sensitivity analysis}

The study doctors could not avoid a 100\% preventiontime-space-deficit rate even if they used $100 \%$ of their direct patient contact time for shared decision making around preventive care. The magnitude of the prevention-time-space-deficit increased substantially when we accounted for the time it takes for doctors to shush patients who try to talk about symptoms, medications, and other health concerns. Yes, the prevention-time-space-deficit could be eliminated if doctors dispensed with shared decision making altogether, and if they limited themselves to only grade A preventive recommendations-but that just brings us full circle to where we started!

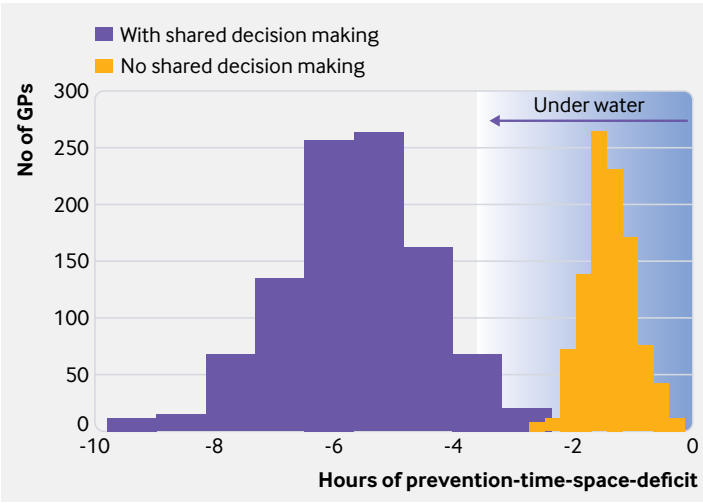

Fig 1 | Distribution of prevention-time-space-deficit across general practitioners

\section{Burnout}

A tried-and-tested option for dealing with unmet demands is to ask doctors to take extra work home (eg, cut into their leisure and grooming and self care time). But even the best options have side effects. We can expect some level of added burnout with each additional hour of work. ${ }^{29}$ Although burnout has the major upside of separating the wheat from the chaff, the magnitude of increased burnout is important, so that the number of resources needed to invest in recruiting replacement doctors can be determined. We developed a handy icon array to help managers determine the number of doctors they would need to replace, due to burnout from the additional hours of work required to complete shared decision making for all preventive services. We found that out of 100 doctors in primary care, there would be 17 additional doctors retiring early due to prevention-time-spacedeficit related burnout (fig 2).

After accepting that a burnout issue exists, clinical managers need to identify potential targets for shoring up time deficits. Figure 3 presents untapped hours in a general practitioner's average day, which highlights several promising domains of doctors' personal time that can be reallocated to work, including time wasted on grooming and self care, leisure, and gratuitous sleeping.

\section{Discussion}

Our study found that across a variety of patient panel sizes and annual hours worked, general practitioners have a $100 \%$ prevention-time-space deficit rate if they engage in shared decision making for highly recommended preventive services. Yet this can be remedied as only about 30 additional hours a week need be reallocated from time spent in grooming and self care (who are they trying to fool?), leisure and vacation time (patient care is leisure), or unnecessary sleep (it wasn't needed during their training, right?). The cost of such a solution is reasonable, leading to only 17 additional early retirements for every 100 doctors. Owing to lack of data and interest, we did not assess the effect on mood, relationships, and quality of care.

We also found that, contrary to their protestations, general practitioners have a lot of spare timepotentially enough within their overall personal care regimens to complete shared decision making for highly recommended preventive services (as well as new clinical initiatives dreamt up by managers).

\section{Strengths and limitations of this study}

Well, it's not exactly sky's the limit because all methods have their limitations, one being that clinical managers cannot reduce the time doctors spend with their family and for sleep to less than zero. A major strength of our study, however, is that it clarifies the urgent need to stuff clinical work into any and all remaining crannies of a doctor's non-working time.

One study that estimated the time it takes doctors to carry out all recommended counseling and preventive 
27 GPs are hanging on by a thread

if 11 more GPs are burnt out by adding shared decision making

6 more GPs are burnt out dealing with all highly recommended preventive services

56 out of 100 GPs are burnt out at baseline

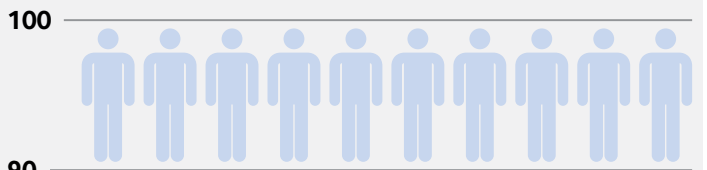

90

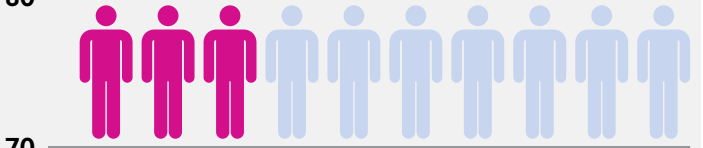

70

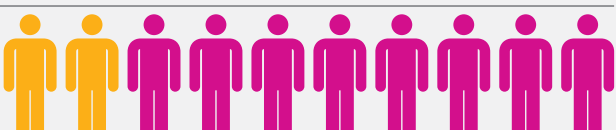

60

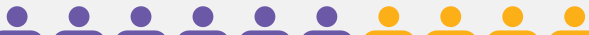

50

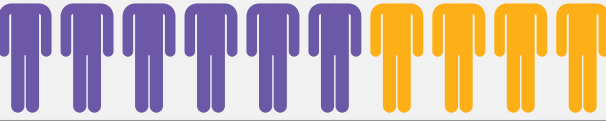

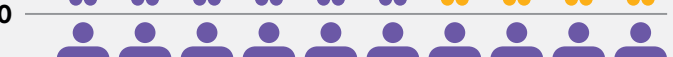

40
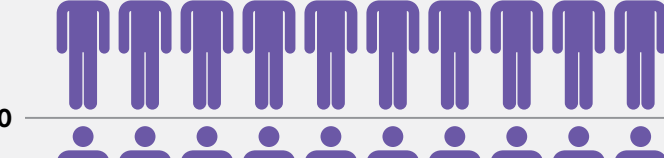

30
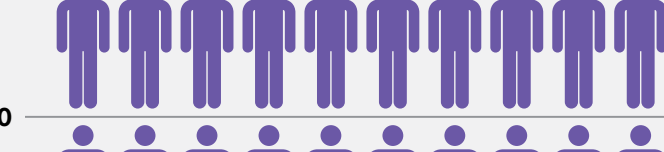

20

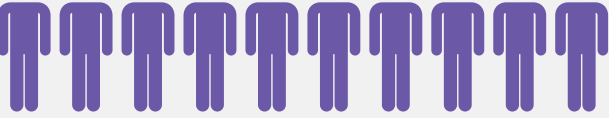

10
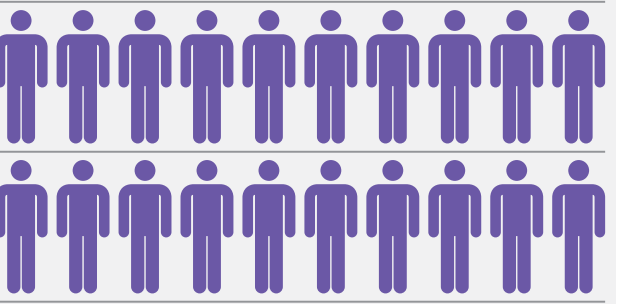

0

Fig 2 | Number of general practitioners (GPs) retiring early owing to additional work hours for preventive services

care was completed before the widespread adoption of electronic health records and did not fully incorporate time for shared decision making. ${ }^{17}$ Our study updates these estimates for the modern era. In addition, our microsimulation approach allowed us to extend this previous work by including variation in visit frequency, panel size, and doctors' work hours. This allowed us to more robustly assess the impossibility of all highly recommended preventive services being delivered successfully unless a doctor's coveted personal time is substantially reduced, and across a variety of panel sizes and clinician practices. We are reasonably confident that the dreadful prevention-time-spacedeficit is not just for the unfortunate few; pretty much all doctors fall short with current allowances of personal time.

\section{Comparison with other studies}

For further study limitations and nitpicky comparisons with past studies, please see the supplement (where we prefer to hide annoying nuances). We all know that inconvenient caveats and boring details can be safely ignored anyway, especially if clinical managers believe they complicate a simple narrative. Also, readers can rest assured that all study limitations are ultimately revealed as hidden strengths.

One possible misinterpretation of our finding of a gross mismatch between the time needed to carry out preventive care and the time available, is that doctors should use clinical judgment to prioritize their time and recommendations for patients. This interpretation may be taken by others ${ }^{30}$ but is clearly ridiculous, since nuanced judgments of clinical value on the basis of detailed clinical information and patient preferences, will only confuse managers seeking to optimize existing performance metrics based on administrative data. Better to skirt the issue of needing to prioritize altogether by first defining clinical tasks (such as shared decision making for all preventive services) as mandatory then labeling them as high priority because they are mandatory. Using this algorithm over time, the only thing that will remain as not high priority will be clinician's personal time, since clinical managers are exceedingly unlikely to make any personal time mandatory.

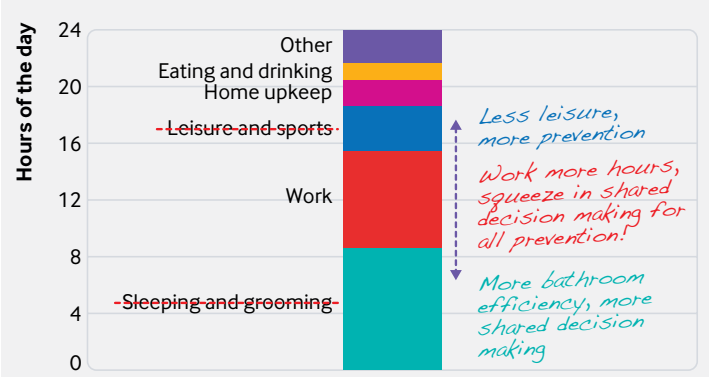

Fig 3 | Identifying vast reservoirs of untapped hours in a general practitioner's average day. Baseline times for each activity are taken from the American Time Use Survey.22 To account for additional time spent working for an average doctor 18 compared with average US adult, one hour was subtracted from the category sleeping and grooming, two hours from leisure and sports, and time for "Other activities not elsewhere classified" was cut entirely. Other activities include housework, food preparation, and lawn care; groceries' shopping, finances, and home and care maintenance; children and family care; care of others in the community; educational activities; religious, civic, and volunteer activities; and telephone calls, mail, and email 


\section{Conclusions and policy implications}

There is not enough time in a doctor's current workday to carry out shared decision making for all highly recommended preventive services. This is because doctors spend too little time working and have too much personal time. In addition, we found that a doctor's personal time is low priority and can instead be better utilized for delivering even low value services, regardless of costs and patient preferences. Future research should explore opportunities for reallocation of doctors' time to other new clinical initiatives. For instance, tapping into doctors' "relaxing and thinking" time ( 0.32 hours of the average day) or "reading for personal interest" time $(0.29 \text { hours })^{22}$ to increase direct access to doctors on demand (eg, through telehealth, email, and Facebook).

\section{Trigger warning}

This satire was written by practicing clinicians, two of whom are general practitioners. The authors do not actually believe that doctors are lazy or sleep too much. The subversive tone is meant to cast a bright light on the impossible set of demands doctors face and the absurdity of ignoring plain facts, such as that a doctor's day cannot exceed 24 hours

TJC was supported by a career development award from the US Veterans Affairs Health Services Research \& Development Program. Contributors: TJC conceived and designed the study and drafted the manuscript. All authors acquired, analyzed, and interpreted the data and critically revised the manuscript for important intellectual content. JFB carried out the statistical analysis. TJC will act as guarantor. The corresponding author attests that all listed authors meet authorship criteria and that no others meeting the criteria have been omitted.

Funding: None.

Competing interests: All authors have completed the ICMJE uniform disclosure form at www.icmje.org/coi disclosure.pdf and declare: no support from any organization for the submitted work; TJC reports a grant from Genentech's Corporate Giving Scientific Program, outside the submitted work. JFB reports personal fees from Astra Zeneca, outside the submitted work. The authors report no other relationships or activities that could appear to have influenced the submitted work. Ethical approval: Not required.

Data sharing: All data and statistical analysis code for this study are available as described in the online technical supplement. Requests for additional information should be directed to tcaverly@med.umich. edu.

Transparency: The lead author (TJC) affirms that the manuscript is an honest, accurate, and transparent account of the study being reported; that no important aspects of the study have been omitted; and that any discrepancies from the study as planned have been explained.

This is an Open Access article distributed in accordance with the Creative Commons Attribution Non Commercial (CC BY-NC 4.0) license, which permits others to distribute, remix, adapt, build upon this work non-commercially, and license their derivative works on different terms, provided the original work is properly cited and the use is noncommercial. See: http://creativecommons.org/licenses/by-nc/4.0/

1 Dugdale DC, Epstein R, Pantilat SZ. Time and the patient-physician relationship. J Gen Intern Med 1999;14(Suppl 1):S34-40. doi:10.1046/j.1525-1497.1999.00263.x

2 Beasley JW, Hankey TH, Erickson R, et al. How many problems do family physicians manage at each encounter? A WReN study. Ann Fam Med 2004:2:405-10. doi:10.1370/afm.94

3 Tai-Seale M, McGuire TG, Zhang W. Time allocation in primary care office visits. Health Serv Res 2007;42:1871-94. doi:10.1111/ j.1475-6773.2006.00689.x
4 Konrad TR, Link CL, Shackelton RJ, et al. It's about time: physicians' perceptions of time constraints in primary care medical practice in three national healthcare systems. Med Care 2010;48:95-100. doi:10.1097/MLR.0b013e3181c12e6a

5 Abbo ED, Zhang Q, Zelder M, Huang ES. The increasing number of clinical items addressed during the time of adult primary care visits. J Gen Intern Med 2008;23:2058-65. doi:10.1007/s11606-0080805-8

6 Jaén CR, Stange KC, Nutting PA. Competing demands of primary care: a model for the delivery of clinical preventive services. J Fam Pract 1994;38:166-71.

7 Flocke SA, Frank SH, Wenger DA. Addressing multiple problems in the family practice office visit. J Fam Pract 2001;50:211-6.

8 Kahneman D. Thinking, Fast and Slow. 1st ed. Farrar, Straus and Giroux, 2011.

9 Friedberg MW, Van Busum K, Wexler R, Bowen M, Schneider EC. A demonstration of shared decision making in primary care highlights barriers to adoption and potential remedies. Health Aff (Millwood) 2013;32:268-75. doi:10.1377/hlthaff.2012.1084

10 Légaré F, Ratté S, Gravel K, Graham ID. Barriers and facilitators to implementing shared decision-making in clinical practice: update of a systematic review of health professionals' perceptions. Patient Educ Couns 2008;73:526-35. doi:10.1016/j.pec.2008.07.018

11 Légaré $F$, Thompson-Leduc P. Twelve myths about shared decision making. Patient Educ Couns 2014;96:281-6. doi:10.1016/j. pec.2014.06.014

12 Sheridan SL, Harris RP, Woolf SH, Shared Decision-Making Workgroup of the U.S. Preventive Services Task Force. Shared decision making about screening and chemoprevention. a suggested approach from the U.S. Preventive Services Task Force. Am J Prev Med 2004;26:5666. doi:10.1016/j.amepre.2003.09.011

13 Brenner AT, Malo TL, Margolis M, et al. Evaluating Shared Decision Making for Lung Cancer Screening. JAMA Intern Med 2018;178:1311-6. doi:10.1001/jamainternmed.2018.3054

14 Rafferty M. Prevention services in primary care: taking time, setting priorities. West / Med 1998;169:269-75.

15 Shires DA, Stange KC, Divine G, et al. Prioritization of evidence-based preventive health services during periodic health examinations. Am J Prev Med 2012;42:164-73. doi:10.1016/j.amepre.2011.10.008

16 Borsky A, Zhan C, Miller T, Ngo-Metzger Q, Bierman AS, Meyers D. Few Americans Receive All High-Priority, Appropriate Clinical Preventive Services. Health Aff (Millwood) 2018;37:925-8. doi:10.1377/ hlthaff.2017.1248

17 Yarnall KS, Pollak KI, Østbye T, Krause KM, Michener JL. Primary care: is there enough time for prevention? Am J Public Health 2003:93:635-41. doi:10.2105/AJPH.93.4.635

18 Leigh JP, Tancredi D, Jerant A, Kravitz RL. Annual work hours across physician specialties. Arch Intern Med 2011;171:1211-3. doi:10.1001/archinternmed.2011.294

19 Christianson JB, Volmar KM, Alexander J, Scanlon DP. A report card on provider report cards: current status of the health care transparency movement. J Gen Intern Med 2010;25:1235-41. doi:10.1007/ s11606-010-1438-2

20 Rosenthal MB, Landon BE, Normand S-LT, Frank RG, Epstein AM. Pay for performance in commercial HMOs. N Engl / Med 2006;355:1895 902. doi:10.1056/NEJMsa063682

21 Maslach C, Schaufeli WB, Leiter MP. Job burnout. Annu Rev Psychol 2001;52:397-422. doi:10.1146/annurev.psych.52.1.397

22 American Time Use Survey. [cited 2018 Aug 31]. www.bls.gov/tus/

23 NHANES - National Health and Nutrition Examination Survey. 2018 [cited 2018 Aug 31]. www.cdc.gov/nchs/nhanes/index.htm

24 NAMCS/NHAMCS - Web Tables. 2018 [cited 2018 Aug 31]. www.cdc gov/nchs/ahcd/web tables.htm

25 Irvine J. ACO Turnover is High. Doctors Have Few Patients, and Those Patients are Unusually Healthy. [cited 2018 Aug 31]. http:// thehealthcareblog.com/blog/2017/05/22/aco-turnover-is-highdoctors-have-few-patients-and-those-patients-are-unusuallyhealthy/

26 HealthDecision. Mammography Tool - Education. www.youtube.com/ watch?v=2anLkjyylbY

27 Statin Choice Decision Aid Visit. [cited 2018 Aug 31]. www.youtube. $\mathrm{com} /$ watch?v=GFRoYPaSH-s

28 Fun with Logical Fallacies. Farnam Street. 2016 [cited 2018 Oct 25] https://fs.blog/2016/07/logical-fallacies/

29 Shanafelt TD, Dyrbye LN, Sinsky C, et al. Relationship Between Clerical Burden and Characteristics of the Electronic Environment With Physician Burnout and Professional Satisfaction. Mayo Clin Proc 2016;91:836-48. doi:10.1016/j.mayocp.2016.05.007

30 Hayward RA. Performance measurement in search of a path. N Engl J Med 2007;356:951-3. doi:10.1056/NEJMe068285

Supplemental material: additional information 